\title{
Differences in endodontic emergency management by endodontists and general dental practitioners in COVID-19 times
}

\author{
Ayfer Atav ATES(a) \\ Taher ALOMAR I(b) ID \\ Anuj BHARDWAJ(c) iD \\ Abedelmalek TABNJH ${ }^{(\mathrm{d})}$ \\ Gianluca GAMBARINI(e) iD \\ (a) Istanbul Okan University, Faculty of \\ Dentistry, Department of Endodontics, \\ Istanbul, Turkey. \\ (b) Jordan University of Science and \\ Technology, Department of Conservative \\ Dentistry, Ar-Ramtha, Jordan. \\ (c) College of Dental Science and Hospital, \\ Department of Conservative Dentistry and \\ Endodontics, Indore, India. \\ (d) Jordan University of Science and \\ Technology, Department of Applied Dental \\ Sciences, Ar-Ramtha, Jordan. \\ (e) Sapienza University of Rome, Department \\ of Oral and Maxillo-Facial Sciences, \\ Rome, Italy.
}

Declaration of Interests: The authors certify that they have no commercial or associative interest that represents a conflict of interest in connection with the manuscript.

Corresponding Author:

Ayfer Atav Ates

E-mail:carminaayfer@hotmail.com
Abstract: The aim of this study was to assess the differences, if any, between general dental practitioners (GDPs) and endodontists, in the diagnosis and treatment of endodontic emergencies during the worldwide outbreak of COVID-19. An online questionnaire was randomly sent by social media to clinicians in different countries from 24 April, 2020 to May 4, 2020. The survey consisted of a series of questions about demographic characteristics, endodontic emergency diagnoses, approaches to prevent aerosol formation, drug prescriptions in case of symptomatic irreversible pulpitis, and the ways in which dentists managed endodontic emergencies during the COVID-19 lockdown. A total of 1,058 dentists responded to the questionnaire; $344(32.6 \%)$ of the participants were endodontists. Slightly less than half of the participants ( $n=485,45.8 \%$ ) worked during the lockdown, but only 303 participants (28.6\%) treated endodontic cases/emergencies. The responses showed agreement between endodontists and GDPs regarding the diagnosis of symptomatic irreversible pulpitis (SIP), symptomatic apical periodontitis (SAP), reversible pulpitis, and asymptomatic irreversible pulpitis (AIP). SIP and SAP were considered an emergency, whereas reversible pulpitis and AIP were not considered an emergency $(p>0.05)$. Non-aerosol-generating procedures and treatment approaches differed between the groups $(p<0.05)$. One-third of the participants did not use rubber dam $(p>0.05)$. Ibuprofen and amoxicillin-clavulanic acid were the most frequently prescribed drugs for pain associated with SIP. In conclusion, the most relevant findings in our survey were the differences between endodontists and GDPs in diagnosis, precheck triage, deep caries excavation procedures, and endodontic emergency pain relief strategies.

Keywords: Coronavirus; COVID-19; Dentistry; Endodontists; Pulpotomy.

\section{Introduction}

At the end of December 2019, an emergent pneumonia outbreak originated in Wuhan City. An isolated virus with characteristics similar to SARS-CoV was reported and eventually led to the genome sequencing of SARS-CoV-2. ${ }^{2}$ A cluster of pneumonia cases, caused by $\beta$-coronavirus, was initially named 2019-nCoV. The World Health Organization (WHO) officially 
named it coronavirus disease 2019 (COVID-19) and declared that there was a global pandemic of the coronavirus disease. On February 11, 2020, the Coronavirus Study Group (CSG) of the International Committee proposed that the new designation for the virus should be SARS-CoV-2.

The infected persons presented with clinical signs and symptoms of fever, cough, fatigue, abnormal chest computed tomography images, and severe respiratory distress. Less common symptoms included sputum production, headache, hemoptysis, and diarrhea. ${ }^{3}$

The isolated virus most likely has an animal origin. ${ }^{4}$ However, the outbreaks add to the evidence that human-to-human transmission of COVID-19 has been growing steadily. ${ }^{5}$

Studies estimated the basic reproduction number (R0) of SARS-CoV-2 to be around $2.2^{6}$ or even higher (ranging from 1.4 to 6.5). ${ }^{7}$ Studies also link the virus to familial clusters of pneumonia, which are most likely to affect elderly males. ${ }^{8}$

COVID-19 is an emerging challenge to dental practitioners and patients, as there is a high risk of cross-infection amongst both. However, despite the risks, acute dental pain might necessitate urgent treatment, as endodontic infections can cause serious pain, ${ }^{9}$ and endodontic emergencies are considered an important category of dental emergencies. ${ }^{10}$ Endodontic emergencies generally result from irreversible pulpitis, causing severe pain, as well as abscess formation from necrotic teeth and fractures caused by trauma. ${ }^{11}$

Given the risks that dental treatment may pose during the outbreak, regular dental treatments have been suspended in many countries around the world, and only emergency treatments are allowed. It is not clear how endodontists and general dentists will react to endodontic emergencies, as many different regulations have been proposed worldwide. ${ }^{12,13}$ This study aimed to evaluate the practice of endodontists (E group) versus general dental practitioners (GDP group) regarding the management of endodontic emergencies during the COVID-19 curfew.

\section{Methodology}

This study was approved by the Human Research and Ethics Committee of the Jordan University of
Science and Technology. A multinational online questionnaire was designed and sent by social media (e.g., e-mail, WhatsApp, and Facebook) to GDPs and endodontists in different countries. The questionnaire consisted of a series of questions about demographic characteristics and about how dentists were managing endodontic emergencies during the COVID-19 outbreak. The online questionnaire was circulated worldwide for two weeks during the time period when curfews were being imposed.

The questionnaire was legitimized using a validation process. This process included content validation, face validation, and pilot study. Content validation involved a group discussion with experts, including three endodontists from Turkey, Jordan, and India, as well as a dental public health specialist. The specialists ensured that the content was clear and suitable and comprehensively covered the topics. The comments and suggestions from the experts' discussion group were reviewed to validate the contents of the questionnaire. During the face validation session, 10 dentists were requested to answer the questions as a pretest, and their feedback was utilized to clarify any misunderstood questions.

The questionnaire consisted of three parts. The first part included six personal and professional questions about the age, sex, education, current work status, and experience of the clinicians. The second part contained two questions about dental services during the lockdown. The dentists who had not treated endodontic cases completed the questionnaire in this second part. The third part concerned dental care provision; it was only for those clinicians who were performing endodontic treatment during the COVID-19 outbreak.

For data collection, G Suite (Google Cloud) was used to distribute the international questionnaire to participants. Participants who did not have a high level of English were asked not to fill out the questionnaire. The responses were analyzed with automatic summarization. Percentages were evaluated according to specialty (endodontists and GDPs) and country.

\section{Statistical analysis}

The data obtained from the questionnaire were analyzed using the Statistical Package for Social 
Sciences (SPSS) (version 25.0, SPSS Inc, Chicago, USA). Descriptive statistics such as mean, standard deviation, and percentages were obtained to describe the studied sample. Pearson's chi-square test was performed to detect any significant differences between endodontists and GDPs and among countries. The significance level was set at 0.05 .

\section{Results}

A total of 1,058 dentists from 36 countries around the world (504 males and 554 females) participated in this study. About $32.5 \%$ of the participants were endodontists, whereas most of the others were GDPs. Their ages ranged from 23 to 78 years, with a mean $(\mathrm{SD})=32.4$ (7.3). Most of the participants were from India (49.3\%), Turkey (29.2\%), and Jordan (7.7\%). The mean (SD) years of experience was 8.1 (7.1), ranging from 1 to 44 years. All participants' characteristics are shown in Table 1. Only those clinicians who received qualification/accredited graduate training in endodontics (master's or specialization program) were included in the endodontists group.

Less than half of the participants $n(\%)=485(45.8)$ were working during the lockdown, and most of them were $n(\%)=382(78.8)$ attending to urgent and emergency cases only. Overall, only $25 \%$ of the participants were performing endodontic treatment (PET group) $n(\%)=303$ (28.6). Figure 1 and Table 2 show the results of the practicing section of the questionnaire.

More than two-thirds of the participants (PET group) were using initial screening via video and/or phone calls to identify patients with suspected or possible COVID-19 infection at the time of scheduling the appointment $\mathrm{n}(\%)=79$ (66.9) of endodontists, $n(\%)=130(70.7)$ of GDPs $(\mathrm{P}>0.05)$. The vast majority of the PET group used a non-contact forehead thermometer for measuring the patient's body temperature $(62.5 \%$ of GDPs and $72.0 \%$ of endodontists) $(p<0.05)$. (Table 2$)$

Most participants of the PET group reported symptomatic irreversible pulpitis (SIP), symptomatic apical periodontitis (SAP), acute apical abscess (AAA), and complicated crown fractures/trauma as emergency cases. However, there were statistically significant
Table 1. Personal and professional data on the clinicians' age, sex, education, current work status, and experience. ( $\mathrm{n}=1,058)$.

\begin{tabular}{|c|c|}
\hline Characteristic & n (\%) \\
\hline Age (in years) & $32.4(7.31)^{*}$ \\
\hline Less than 40 & $904(85.5)$ \\
\hline 40 or more & $154(14.5)$ \\
\hline Experience (in years) & $8.1(7.1)^{*}$ \\
\hline$<5$ & $414(39.2)$ \\
\hline $5-10$ & $361(34.2)$ \\
\hline$>10$ & $283(26.8)$ \\
\hline \multicolumn{2}{|l|}{ Sex } \\
\hline Male & $504(47.6)$ \\
\hline Female & $554(52.4)$ \\
\hline \multicolumn{2}{|l|}{ Specialty } \\
\hline Endodontists & $344(32.6)$ \\
\hline GDPs & $711(67.4)$ \\
\hline \multicolumn{2}{|l|}{ Country of residence } \\
\hline Jordan & $81(7.7)$ \\
\hline India & $521(57)$ \\
\hline Turkey & $309(29.2)$ \\
\hline Other countries & $147(6.1)$ \\
\hline \multicolumn{2}{|l|}{ Working place } \\
\hline University clinics & $298(28.2)$ \\
\hline Military sector & $26(2.5)$ \\
\hline Private sector & $590(55.8)$ \\
\hline Public sector & $144(13.6)$ \\
\hline \multicolumn{2}{|l|}{ Practice part } \\
\hline \multicolumn{2}{|c|}{ Are you currently practicing during lockdown? } \\
\hline Yes & $103(9.7)$ \\
\hline Only for urgent and emergency cases & $382(36.1)$ \\
\hline No & $572(54.1)$ \\
\hline \multicolumn{2}{|l|}{ Are you treating endodontic cases? } \\
\hline Yes & $303(28.6)$ \\
\hline No & $755(71.4)$ \\
\hline
\end{tabular}

differences in the diagnosis of chronic apical abscess, AAA, and complicated crown fractures/trauma when comparing the endodontists and GDP groups $(p<0.05)$. The percentages of the results regarding the diagnosis are shown in Figure 1.

Rubber dam was not used by $35.5 \%$ of the GDP group and $27.1 \%$ of the E group while practicing during the COVID-19 outbreak ( $p>0.05)$. About half of those using rubber dam did not cover the patient's nose $(44.6 \%$ of endodontists and $52.5 \%$ of GDPs) $(\mathrm{p}>0.05)$ (Table 2). 


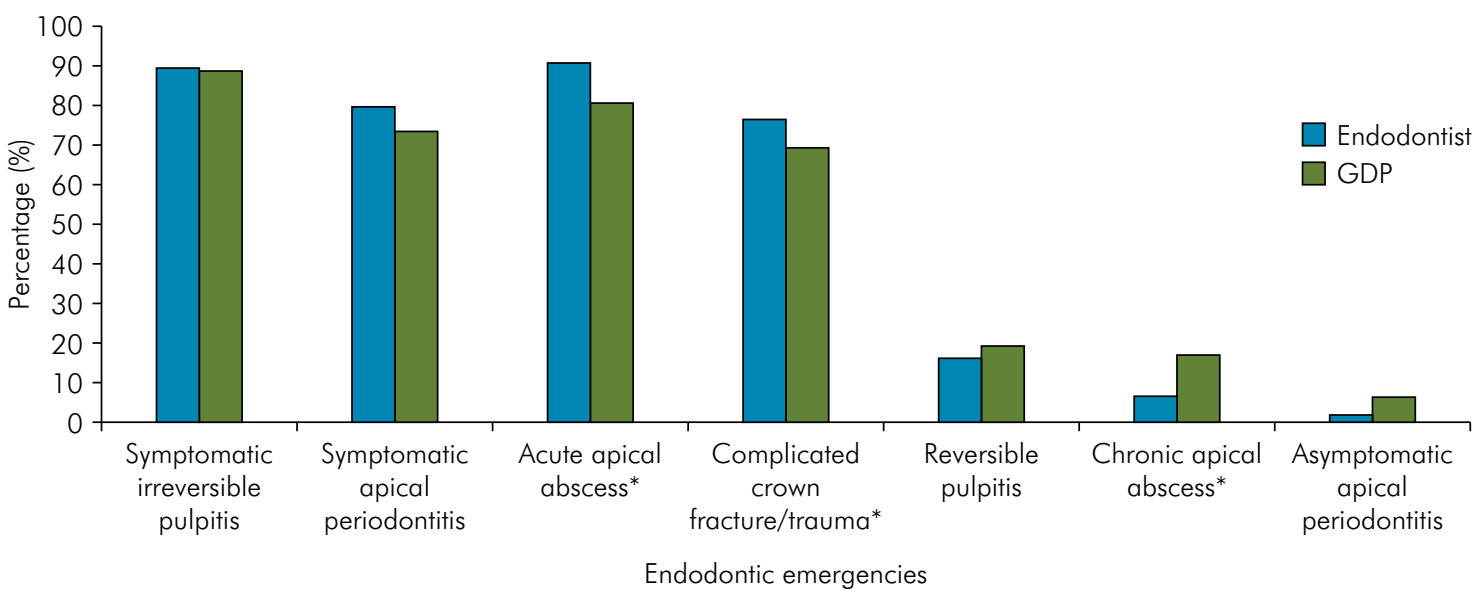

*Significant difference.

Figure 1. Percentages of the results regarding the considered diagnosis of endodontic emergencies by endodontists and general dental practitioners.

Either pulpectomy or pulpotomy was performed by $61.9 \%$ of the E group and $54.1 \%$ of the GDP group in the presence of pain caused by SIP/SAP. Medication alone, without any intervention, was prescribed by $27.9 \%$ of the GDP group and $15.3 \%$ of the E group. Local anesthesia was administered and medication was prescribed for primary pain management by $8.7 \%$ of the GDP group and $14.4 \%$ of the E group (Table 2) $(\mathrm{p}>0.05)$.

Amoxicillin-clavulanic acid was the most common (46.2\%) antibiotic used by both the E and GDP groups for patients with SIP/SAP, whereas ibuprofen was the most commonly used $(49.3 \%)$ analgesic $(p>0.05)$. Only $35.7 \%$ of the E and $28.2 \%$ of GDP groups reported not prescribing antibiotics in SIP/SAP cases. (Table 2)

The use of a slow-speed micromotor without water for access cavity preparation ( $p>0.05)$ was reported by $48.7 \%$ of the E and $43.1 \%$ of the GDP groups. During deep caries excavation, whenever possible, most participants preferred to use a slow-speed micromotor without water spray to prevent aerosol production (66.7\% of the E and $56.6 \%$ of the GDP groups) ( $p>0.05)$ (Table 2).

About half of clinicians performed a partial treatment (pulpotomy) for interim relief instead of a complete treatment (pulpectomy). There was an association between specialty groups and the treatment choice for interim relief (Pearson's chi-square $=14.651$, p < 0.05). Namely, endodontists used complete treatment (pulpectomy) more than did GDPs (61.0\% of the $\mathrm{E}$ and $39.3 \%$ of the GDP groups) (Table 2).

Comparisons between countries were also made in relation to procedures suggested by the government (e.g., remote consultations) and to drug administration. These results are shown in Figures 2 and 3.

\section{Discussion}

COVID-19 has caused radical changes in dentistry, as in many other areas. On March 15, 2020, a news article published in The New York Times by Lazaro Gamio stated that among the various professions, it is the dentists who are most in peril because of this pandemic..$^{14}$ One of the reasons for this has to do with the aerosol that is emitted by the rotary motors during dental treatments. Many countries provided recommendations during the epidemic to avoid the generation of droplets and aerosol. Since no vaccine or antidote has been discovered to date, practitioners will need to implement stricter and more effective infection control protocols in the coming months, in order to be able to reopen dental facilities immediately after the lockdown. The purpose of this questionnaire was to assess differences, if any, in the diagnosis and treatment of endodontic emergencies between GDPs and endodontists in COVID-19 times.

The present survey was conducted during a period of lockdown, which imposed limitations on people's 
Table 2. Questionnaire questions, given answers, and their percentages by endodontists (E) and general dental practitioners (GDP).

\begin{tabular}{|c|c|c|c|c|}
\hline \multirow{4}{*}{ Variable } & \multicolumn{2}{|c|}{ Group ( $\mathrm{n}=303$ ) } & \multirow{4}{*}{$\begin{array}{l}\text { Chi-square } \\
\text { test }\end{array}$} & \multirow{4}{*}{ p-value } \\
\hline & E group & GDP & & \\
\hline & $\mathrm{n}=119$ & $\mathrm{n}=184$ & & \\
\hline & n (\%) & n (\%) & & \\
\hline \multicolumn{3}{|c|}{$\begin{array}{l}\text { Do you use initial screening via video and/or phone calls to identify patients with suspected or possible } \\
\text { COVID-19 infection at the time of scheduling appointments? (Remote Consultation) }\end{array}$} & 0.463 & 0.496 \\
\hline Yes & $79(66.9)$ & $130(70.7)$ & & \\
\hline No & $39(33.1)$ & $54(29.3)$ & & \\
\hline \multicolumn{2}{|l|}{ Do you measure the patients' body temperature upon patient arrival at your clinic? } & & 7.869 & $0.020^{*}$ \\
\hline Yes (traditional methods) & $21(17.8)$ & $27(14.7)$ & & \\
\hline Yes (non-contact forehead thermometer) & $85(72.0)$ & $115(62.5)$ & & \\
\hline No & $12(10.2)$ & $42(22.8)$ & & \\
\hline \multicolumn{2}{|l|}{ Do you use the rubber dam? } & & 3.225 & 0.358 \\
\hline Yes, before access cavity preparation & $49(41.45)$ & $61(33.3)$ & & \\
\hline Yes, after access cavity preparation & $14(11.9)$ & $25(13.7)$ & & \\
\hline Sometimes & $23(19.5)$ & $32(17.5)$ & & \\
\hline No & $32(27.1)$ & $65(35.5)$ & & \\
\hline \multicolumn{2}{|l|}{ If you use the rubber dam; do you cover the nose? } & & 1.312 & 0.252 \\
\hline Yes & $51(55.4)$ & $57(47.5)$ & & \\
\hline No & $41(44.6)$ & $63(52.5)$ & & \\
\hline \multicolumn{3}{|c|}{$\begin{array}{l}\text { Regarding the primary management of patients with symptomatic irreversible pulpitis and symptomatic apical } \\
\text { periodontitis (during COVID-19 outbreak), you: }\end{array}$} & 7.911 & 0.095 \\
\hline Prescribe medicine only & $18(15.3)$ & $51(27.9)$ & & \\
\hline Local anesthesia + medicine (antibiotics/analgesics) & $17(14.4)$ & $16(8.7)$ & & \\
\hline Local anesthesia + dexamethasone & $5(4.2)$ & $9(4.9)$ & & \\
\hline Treatment (pulpotomy/pulpectomy) & $73(61.9)$ & $99(54.1)$ & & \\
\hline Tooth extraction & $5(4.2)$ & $8(4.4)$ & & \\
\hline \multicolumn{3}{|c|}{$\begin{array}{l}\text { Which antibiotic is your first choice for a patient with symptomatic irreversible pulpitis with severe pain? (During } \\
\text { COVID-19 outbreak) }\end{array}$} & 9.697 & 0.138 \\
\hline Do not prescribe & $41(35.7)$ & $50(28.2)$ & & \\
\hline Amoxicillin-clavulanic acid & $48(41.7)$ & $87(49.2)$ & & \\
\hline Amoxicillin & $14(12.2)$ & $32(18.1)$ & & \\
\hline Penicillin & $5(4.3)$ & $6(3.4)$ & & \\
\hline Others (metronidazole, azithromycin, cefpodoxime) & $7(6.1)$ & $2(1.2)$ & & \\
\hline \multicolumn{3}{|c|}{$\begin{array}{l}\text { Which analgesic is your first choice for a patient with symptomatic irreversible pulpitis with severe pain? (During } \\
\text { COVID-19 outbreak) }\end{array}$} & 2.361 & 0.670 \\
\hline Do not prescribe & $3(2.8)$ & $5(3.0)$ & & \\
\hline Ibuprofen 600 mg & $51(48.1)$ & $84(50.0)$ & & \\
\hline Acetaminophen & $23(21.7)$ & $31(18.5)$ & & \\
\hline Ketorolac tromethamine & $16(15.1)$ & $34(20.2)$ & & \\
\hline Flurbiprophen & $13(12.3)$ & $14(8.3)$ & & \\
\hline \multicolumn{2}{|l|}{ Which one do you use during access cavity preparation? (During COVID-19 outbreak) } & & 3.797 & 0.284 \\
\hline Aerator and slow-speed micromotor with water & $55(47.8)$ & $92(50.8)$ & & \\
\hline Aerator and slow-speed micromotor without water & $56(48.7)$ & $78(43.1)$ & & \\
\hline Other (laser, ultrasonics) & $4(3.5)$ & $11(6.1)$ & & \\
\hline
\end{tabular}




\begin{tabular}{|c|c|c|c|c|}
\hline \multirow{4}{*}{ Variable } & \multicolumn{2}{|c|}{ Group $(n=303)$} & \multirow{4}{*}{$\begin{array}{c}\text { Chi-square } \\
\text { test }\end{array}$} & \multirow{4}{*}{ p-value } \\
\hline & E group & GDP & & \\
\hline & $\mathrm{n}=119$ & $\mathrm{n}=184$ & & \\
\hline & $\mathrm{n}(\%)$ & $\mathrm{n}(\%)$ & & \\
\hline What do you use for deep caries excavation, if possible? (During COVID-19 outbreak) & & & 6.242 & $0.044^{*}$ \\
\hline Slow-speed micromotor without water spray & $78(66.7 \%)$ & $99(56.6 \%)$ & & \\
\hline Sharp spoon excavator & $29(24.8 \%)$ & $43(24.6 \%)$ & & \\
\hline Carisolv + sharp spoon excavator & $10(8.5 \%)$ & $33(18.9 \%)$ & & \\
\hline What would be the choice for interim relief for vital teeth? (During COVID-19 outbreak) & & & 14.651 & $0.005^{*}$ \\
\hline Pulpectomy with endodontic instruments & $72(61.0)$ & $72(39.3)$ & & \\
\hline $\begin{array}{l}\text { Place a cotton pellet with eugenol liquid /devitalizing agent in the pulp chamber } \\
\text { (after pulpotomy) }\end{array}$ & $34(28.8)$ & $75(41.0)$ & & \\
\hline Place a sterile cotton pellet after coronal pulpotomy & $8(6.8)$ & $27(14.8)$ & & \\
\hline Perform MTA after pulpotomy & $4(3.4)$ & $9(4.9)$ & & \\
\hline
\end{tabular}

${ }^{*}$ p-value significant $<0.05$.

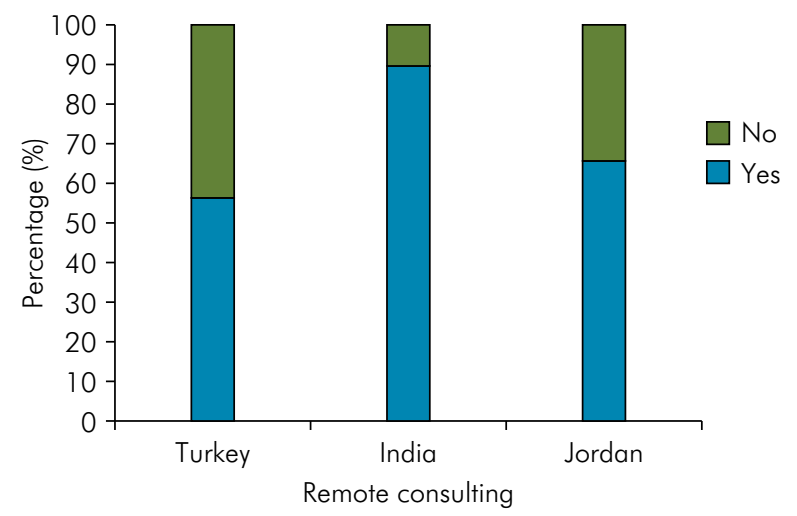

Figure 2. Comparison of remote consultation percentages for India, Turkey, and Jordan.

movement and on dental activities. Only 485 of the 1,058 dentists who answered this questionnaire treated patients. Of these, only 303 practitioners ( $n=119$ for the $E$ and $n=184$ for the GDP groups) treated endodontic cases. Remote consultation became a common procedure for both groups: $70.7 \%$ of GDPs and $66.9 \%$ of endodontists indicated that they primarily used video and/or phone calls to identify emergencies and possible COVID-19 infected patients, by asking questions such as: in the last 14 days has your body temperature increased?; or did you travel from/to at-risk regions? More precisely, there was a correlation between the country and the preference for remote consultation $(\mathrm{p}<0.05)$. The vast majority

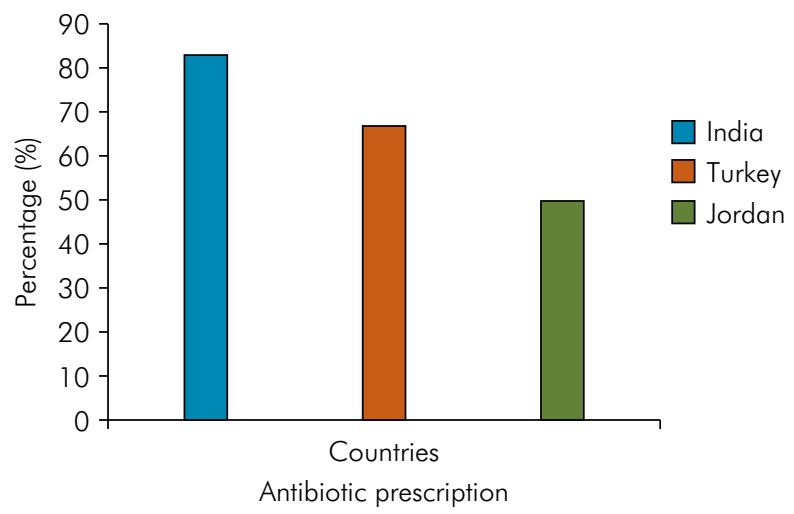

Figure 3. Percentages of antibiotic prescription for India, Turkey, and Jordan in case of symptomatic irreversible pulpitis.

of Indian dentists (90.5\%), who were working during the lockdown, offered remote consultation instead of an immediate appointment at dental clinics. On the other hand, this percentage decreased among Turkish dentists (56.3\%); this may be related to the lack of a strict curfew in that country, or a lower perception of contagion risk.

In the practice part of the questionnaire, at first, the in-office triage procedures of clinicians were analyzed. The majority of the respondents reported that they measured the body temperature of the patients (62.9\% contact-free forehead thermometer, $18.4 \%$ traditional measuring methods). Conversely, $22.8 \%$ of GDPs and $10.2 \%$ of endodontists did not 
measure body temperature before starting dental treatments $(p<0.05)$, despite many government recommendations emphasizing that the patient's body temperature should be measured with a contact-free forehead thermometer in the precheck triage as a routine procedure. ${ }^{3}$ It is logical to assume that governments should introduce legislation that requires these procedures to be mandatory (rather than only recommended) in the near future.

During the lockdown in most countries, only emergency dental procedures were allowed. However, in most countries, there was no clear specification of what constituted a dental emergency at the beginning of the pandemic. In many dental settings worldwide, diagnosis and emergency treatment were mostly dependent on clinical experience, skills, or attitude. It was the dentist who decided which patient was an emergency, and which one was not. This is well documented by the results of the present survey. The study results show that some cases such as SIP and SAP were considered as an emergency, whereas reversible pulpitis and asymptomatic apical periodontitis were not considered an emergency by a high percentage of both endodontists and GDPs ( $p>0.05)$. In other kinds of emergencies, such as chronic apical abscess, AAA, and complicated crown fractures/trauma, there were statistical differences in the diagnoses between GDP and endodontists $(\mathrm{p}<0.05)$. The reason for these differences can be explained by the differences in the amount and type of emergencies: endodontists were dealing only with pain and swelling from pulpal/periapical tissues or dental trauma, whereas dentists were managing many other emergencies such as pericoronitis, painful lesions/ulcerations of the oral mucosa, as well as endodontic emergencies during this period. Therefore, the perspective and attitude of dentists towards endodontic emergencies was slightly different from that of endodontists. In a recent study by Yu et al., ${ }^{15}$ SIP was found to be the most common reason for referral to dental clinics during the pandemic. In parallel with this result, clinicians in this study indicated that SIP was seen as an emergency diagnosis. A previous study reported that GDPs considered SIP (93.3-99\%) and AAA (99\%) to be an emergency requiring treatment. ${ }^{16}$ In our study, a high percentage of endodontists $(92.4 \%)$ and
GDPs (82.1\%) responded that they considered AAA to be an emergency diagnosis $(p<0.05)$.

In the present study, $78.2 \%$ of endodontists and $66.3 \%$ of GDP accepted complicated crown fractures/trauma as an emergency $(p<0.05)$. This statistical difference could be explained by a lack of knowledge among dentists about dental trauma and management strategies, as mentioned by $\mathrm{Hu}$ et al. ${ }^{17}$

Endodontic treatment can be performed mechanically, which is traditional, or in an emergency case, it can be facilitated by medications (anesthesia, drugs, and antibiotics). Any medications can be prescribed as an adjunct to endodontic treatment. Ather et al. ${ }^{18}$ reported that prescribing medicine (ibuprofen $600 \mathrm{mg}+$ acetaminophen $325-500 \mathrm{mg}$ and dexamethasone $0.07-0.09 \mathrm{mg} / \mathrm{kg}$ ) and applying longacting anesthetics are part of the armamentarium used for primary management of dental pain caused by SIP/SAP without any mechanical treatment during the COVID-19 outbreak. In this study, 27.9\% of GDPs and $15.3 \%$ of endodontists reported that they prescribe only medicine without any intervention. Also, $8.7 \%$ of GDPs and $14.4 \%$ of endodontists administered local anesthesia, in addition to prescribing medication for primary pain management. These results reveal that participants were aware of published guidelines and the risk of disease transmission due to the aerosol that is emitted during treatment. A low percentage (4.7\%) of participants reported prescribing dexamethasone. Perhaps, the reason for this can be related to the statement, given on March 16, 2020 by the Belgian Federal Agency for Medicines and Health Products, which warned of corticosteroids' severe complications on COVID-19-positive patients. ${ }^{19}$

Concerning the question about analgesic prescription in the presence of SIP/SAP, $97 \%$ of GDPs and $96.8 \%$ of endodontists chose to prescribe painkillers. There was no significant difference between GDPs and endodontists ( $p>0.05)$, and ibuprofen was the most preferred pain reliever (49.3\% of all participants). This result is similar to a finding by Mickel et al. ${ }^{20}$ that ibuprofen is a popular drug preferred by clinicians in the presence of endodontic pain. However, during the pandemic, French authorities stated that the use of NSAI was not recommended because COVID-19-infected 
individuals who took ibuprofen had experienced a worsening of symptoms..$^{21} \mathrm{WHO}$ has also confirmed the accuracy of this opinion and has suggested the use of acetaminophen instead of ibuprofen, as many COVID-19-positive individuals are not aware of having this disease..$^{22}$ Nevertheless, this knowledge did not seem to change the choice of painkillers commonly used for endodontic pain, as shown by a lower percentage of clinicians (19.7\%) who preferred acetaminophen in the present study.

Participants were also asked which antibiotic was prescribed in the case of SIP/SAP. Most participants (64.3\% of endodontists, $71.8 \%$ of GDPs) reported that they prescribed antibiotics in SAP/SIP cases during the pandemic $(p>0.05)$. Furthermore, our results show that Turkish (69.9\%) and Indian (86.1\%) dentists had higher rate of prescription of antibiotics, which is in agreement with a previous study by Segura-Egea et al. ${ }^{23}$ These results show that these dentists tend to prescribe more drugs to patients just to be more confident both during and before the pandemic. This might be related to striving to offer patients a more comfortable postoperative period; obviously, antibiotics are never indicated by the dentists for SIP. Additionally, amoxicillin-clavulanic acid was the first choice of both the GDPs and endodontists, similar to the study of Khan et al. ${ }^{24}$ This might be due to the broad-spectrum of this drug, low incidence of resistance, and pharmacokinetic profile, in addition to factors related to tolerance and dosage. ${ }^{25}$

SIP is one of the most challenging cases for clinicians due to pain intensity. Pulpectomy is generally the recommended therapeutic option if there is enough time for completing the treatment. ${ }^{26}$ However, during COVID-19 times, when dentists were asked to treat mainly dental emergencies, rapid and effective management methods for treating severe pain of endodontic origin had to be utilized. ${ }^{27}$ Several studies ${ }^{28-30}$ demonstrate that pulpotomy could be a quick and simple pain-relieving approach in endodontic emergency treatment. This may be the reason why only $39.3 \%$ of the GDPs performed pulpectomy. On the contrary, the vast majority (61\%) of the endodontists preferred to complete treatment and perform pulpectomy. The difference in approach between GDP and endodontists may be due to different skills and levels of confidence about pulpectomy, which is a more effective and predictable procedure. ${ }^{30} \mathrm{~A}$ study by Hasselgren and Reit ${ }^{31}$ concluded that pulpectomy alone is a valid procedure for endodontic emergencies, regardless of the sedative dressing agents. Nevertheless, in our questionnaire, $41 \%$ of GDPs did not complete the root canal treatment, but rather placed eugenol liquid or a devitalizing agent to the pulp chamber, instead of performing pulpectomy.

Aerosols are normally generated while removing caries and opening an endodontic access cavity; they can be inhaled, absorbed by the skin and by personal protective equipment, or can set in nearby surfaces, thereby causing the transmission of SARS-CoV-2. ${ }^{32}$ Therefore, reducing the production of aerosols, given the increased risk of cross-contamination, is a significant concern during endodontic procedures. To lower the risk of airborne infections, the following recommendations were made during the COVID-19 lockdown: avoiding the unnecessary production of aerosols; protecting clinicians better with personal protection equipment, protecting the environment better; and using the rubber dam. Many countries have issued declarations on aerosol-related procedures. ${ }^{12,13}$ In the questionnaire, several questions were asked to assess what dentists have been doing to reduce the risk from aerosols in COVID-19 times. The first question concerned rubber dam usage. In this survey, which was conducted at the time when COVID-19 peaked in the world, 35.5\% of GDPs and $27.1 \%$ of endodontists still did not use a rubber dam while practicing $(p>0.05)$, despite the risk of aerosols and the given recommendations. Moreover, approximately half of the endodontists and GDPs who used a rubber dam did not cover the patient's nose with the rubber dam during the treatment. This might be related to underestimating the risk of infection spread by aerosol or to a lack of endodontic knowledge. As emphasized in many recommendations, ${ }^{31}$ clinicians should implement the use of a rubber dam by strict rules during and after the pandemic.

It is difficult to precisely provide guidelines about avoiding the generation of aerosols. Some suggested guidelines could be: using more powerful 
suction devices or aerators, and using a low-speed micromotor without water for access. In our study, $48.7 \%$ of endodontists and $43.1 \%$ of GDPs used lowspeed motors without water to minimize the risk $(p>0.05)$. This is an easy, affordable, and inexpensive solution, but it obviously makes the procedure more difficult to perform. If possible, chemomechanical caries removal and hand instrumentation with sharp spoon excavators could also be good options for deep caries excavation ${ }^{15}$ during these COVID-19 times. The results of the current study show that the use of these methods by GDPs (43.5\%) is more common than by endodontists $(33.3 \%)(p<0.05)$. The proposed methods are less efficient than aerosol-producing high-speed burs, which may explain why endodontists, who generally treat more complex cases, tended to use this alternative and less efficient method less frequently.

Similar to other questionnaires, the present study had the following limitations: the options of the survey questions did not reflect every situation in the clinical practice; the differences between regulations may have influenced different clinical behaviors, and finally, the abnormal distribution of the participants from
36 countries. Questions and multiple-choice answers were specifically formulated in a simple and direct way to avoid misunderstandings that could generate wrong results. The questionnaire was simple to read and complete in a short amount of time. Despite the limitations mentioned above, the questionnaire was able to depict a clear picture of clinicians' behaviors during the COVID-19 lockdown.

\section{Conclusion}

Hence, we may conclude that GDPs and endodontists differ in some major findings such as endodontic emergency diagnoses and pain relief strategies, precheck triage including body temperature measurements, and deep caries excavation procedures related to aerosol prevention strategies. Guidelines should be implemented to harmonize clinical approaches between GDP and endodontists.

\section{Acknowledgments}

We would like to express our thanks and appreciation to all participants who completed the survey.

\section{References}

1. Zhu N, Zhang D, Wang W, Li X, Yang B, Song J, et al.; China Novel Coronavirus Investigating and Research Team. A Novel Coronavirus from Patients with Pneumonia in China, 2019. N Engl J Med. 2020 Feb;382(8):727-33. https://doi.org/10.1056/NEJMoa2001017

2. Lu R, Zhao X, Li J, Niu P, Yang B, Wu H, et al. Genomic characterisation and epidemiology of 2019 novel coronavirus: implications for virus origins and receptor binding. Lancet. 2020 Feb;395(10224):565-74. https://doi.org/10.1016/S0140-6736(20)30251-8

3. Peng X, Xu X, Li Y, Cheng L, Zhou X, Ren B. Transmission routes of 2019-nCoV and controls in dental practice. Int J Oral Sci. 2020 Mar;12(1):9. https://doi.org/10.1038/s41368-020-0075-9

4. Andersen KG, Rambaut A, Lipkin WI, Holmes EC, Garry RF. The proximal origin of SARS-CoV-2. Nat Med. 2020 Apr;26(4):450-2. https://doi.org/10.1038/s41591-020-0820-9

5. Guo YR, Cao QD, Hong ZS, Tan YY, Chen SD, Jin HJ, et al. The origin, transmission and clinical therapies on coronavirus disease 2019 (COVID-19) outbreak-an update on the status. Mil Med Res. 2020;7(1):1-10. https://doi.org/10.1186/s40779-020-00240-0

6. Riou J, Althaus CL. Pattern of early human-to-human transmission of Wuhan 2019 novel coronavirus (2019-nCoV), December 2019 to January 2020. Euro Surveill. 2020 Jan;25(4):2000058. https://doi.org/10.2807/1560-7917.ES.2020.25.4.2000058

7. Liu Y, Gayle AA, Wilder-Smith A, Rocklöv J. The reproductive number of COVID-19 is higher compared to SARS coronavirus. J Travel Med. 2020 Mar;27(2):4. https://doi.org/10.1093/jtm/taaa021

8. Chan JF, Yuan S, Kok KH, To KK, Chu H, Yang J, et al. A familial cluster of pneumonia associated with the 2019 novel coronavirus indicating person-to-person transmission: a study of a family cluster. Lancet. 2020 Feb;395(10223):514-23. https://doi.org/10.1016/S0140-6736(20)30154-9

9. McCarthy PJ, McClanahan S, Hodges J, Bowles WR. Frequency of localization of the painful tooth by patients presenting for an endodontic emergency. J Endod. 2010 May;36(5):801-5. https://doi.org/10.1016/i.joen.2009.12.035

10. Huang SM, Huang JY, Yu HC, Su NY, Chang YC. Trends, demographics, and conditions of emergency dental visits in Taiwan 1997-2013: A nationwide population-based retrospective study. J Formos Med Assoc. 2019 Feb;118(2):582-7. https://doi.org/10.1016/i.jfma.2018.11.012 
Differences in endodontic emergency management by endodontists and general dental practitioners in COVID-19 times

11. Sutherland S. Antibiotics do not reduce toothache caused by irreversible pulpitis. Are systematic antibiotics effective in providing pain relief in people who have irreversible pulpitis? Evid Based Dent. 2005;6(3):67. https://doi.org/10.1038/sj.ebd.6400340

12. Krithikadatta J, Nawal RR, Amalavathy K, McLean W, Gopikrishna V. Endodontic and dental practice during COVID-19 pandemic: position statement from International Federation of Endodontic Associations (IFEA) \& Indian Endodontic Society (IES): Faculty of Dentistry, Sri Ramachandra University, Chennai, India. Endodontology. 2020;32(2):55-66. https://doi.org/10.4103/endo.endo_61_20

13. Bhanderi S, Lessani M, Morgan A, Tomson P, McLean W. Diagnosis and management of endodontic emergencies, a british endodontic society position paper for primary dental care and other healthcare providers during the COVID-19 pandemic. 2020.

14. Gamio L. The workers who face the greatest coronavirus risk. New York Times,. 2020 Mar 15 [cited 2020 May 3]. Available from: https://www.nytimes.com/interactive/2020/03/15/business/economy/coronavirus-worker-risk.html

15. Ganesh M, Parikh D. Chemomechanical caries removal (CMCR) agents: review and clinical application in primary teeth. J Dent Oral Hyg. 2011;3(3):34-45.

16. Bestall S, Flynn R, Charleson G, Abbott PV. Assessment of Australian Dentists' Treatment Planning Decisions Based on Diagnosis. J Endod. 2020 Apr;46(4):483-9. https://doi.org/10.1016/i.joen.2020.01.004

17. Hu LW, Prisco CR, Bombana AC. Knowledge of Brazilian general dentists and endodontists about the emergency management of dentoalveolar trauma. Dent Traumatol. 2006 Jun;22(3):113-7. https://doi.org/10.1111/j.1600-9657.2006.00341.x

18. Ather A, Patel B, Ruparel NB, Diogenes A, Hargreaves KM. Coronavirus Disease 19 (COVID-19): Implications for Clinical Dental Care. J Endod. 2020 May;46(5):584-95. https://doi.org/10.1016/i.joen.2020.03.008

19. Russell B, Moss C, Rigg A, Van Hemelrijck M. COVID-19 and treatment with NSAIDs and corticosteroids: should we be limiting their use in the clinical setting? Ecancermedicalscience. 2020 Mar;14:1023. https://doi.org/10.3332/ecancer.2020.1023

20. Mickel AK, Wright AP, Chogle S, Jones JJ, Kantorovich I, Curd F. An analysis of current analgesic preferences for endodontic pain management. J Endod. 2006 Dec;32(12):1146-54. https://doi.org/10.1016/i.joen.2006.07.015

21. Day M. Covid-19: ibuprofen should not be used for managing symptoms, say doctors and scientists. Br Med J. 2020;368:m1086. https://doi.org/10.1136/bmi.m1086

22. Sodhi M, Etminan M. Safety of Ibuprofen in Patients With COVID-19: causal or Confounded? Chest. 2020 Jul;158(1):55-6. https://doi.org/10.1016/i.chest.2020.03.040

23. Segura-Egea JJ, Martín-González J, Jiménez-Sánchez MD, Crespo-Gallardo I, Saúco-Márquez JJ, Velasco-Ortega E. Worldwide pattern of antibiotic prescription in endodontic infections. Int Dent J. 2017 Aug;67(4):197-205. https://doi.org/10.1111/idj.12287

24. Khan SI, Asghar S, Faizan SM. Current Trends To Deal Endodontic Emergencies and Use of Antibiotics by Dentists of Karachi. J Pak Dent Assoc. 2018;27(1):18-21. https://doi.org/10.25301/JPDA.271.18

25. Kuriyama T, Williams DW, Yanagisawa M, Iwahara K, Shimizu C, Nakagawa K, et al. Antimicrobial susceptibility of 800 anaerobic isolates from patients with dentoalveolar infection to 13 oral antibiotics. Oral Microbiol Immunol. 2007 Aug;22(4):285-8. https://doi.org/10.1111/j.1399-302X.2007.00365.x

26. Lee M, Winkler J, Hartwell G, Stewart J, Caine R. Current trends in endodontic practice: emergency treatments and technological armamentarium. J Endod. 2009 Jan;35(1):35-9. https://doi.org/10.1016/i.joen.2008.10.007

27. Yu J, Zhang T, Zhao D, Haapasalo M, Shen Y. Characteristics of Endodontic Emergencies during Coronavirus Disease 2019 Outbreak in Wuhan. J Endod. 2020 Jun;46(6):730-5. https://doi.org/10.1016/i.joen.2020.04.001

28. Nyerere JW, Matee MI, Simon EN. Emergency pulpotomy in relieving acute dental pain among Tanzanian patients. BMC Oral Health. 2006 Jan;6(1):1. https://doi.org/10.1186/1472-6831-6-1

29. Asgary S, Eghbal MJ. The effect of pulpotomy using a calcium-enriched mixture cement versus one-visit root canal therapy on postoperative pain relief in irreversible pulpitis: a randomized clinical trial. Odontology. $2010 \mathrm{Jul} ; 98(2): 126-33$. https://doi.org/10.1007/s10266-010-0127-2

30. Eren B, Onay EO, Ungor M. Assessment of alternative emergency treatments for symptomatic irreversible pulpitis: a randomized clinical trial. Int Endod J. 2018 Apr;51 Suppl 3:e227-37. https://doi.org/10.1111/iej.12851 PMID:28857203

31. Hasselgren G, Reit $C$. Emergency pulpotomy: pain relieving effect with and without the use of sedative dressings. J Endod. 1989 Jun;15(6):254-6. https://doi.org/10.1016/S0099-2399(89)80219-5

32. World Health Organization - WHO. Modes of transmission of virus causing COVID-19: implications for IPC precaution recommendations: scientific brief, 27 March 2020. Geneva: World Health Organization; 2020 [cited 2020 Mar 27]. Available from: https://apps.who.int/iris/handle/10665/331601 